\title{
Assessment of the impact of the urbanized territory of Yekaterinburg city on the formation of undergrowth in the forest park zone
}

\author{
Olga Tolkach, and Olga Dobrotvorskaya \\ Botanical Garden of the Ural Branch of the Russian Academy of Sciences Yekaterinburg. Russia
}

\begin{abstract}
Resume. The parameters of the undergrowth in the forbs and berry groups of pine forest types in 9 parks in Yekaterinburg and areas of natural forest have been investigated. Data on the species composition, density, and distribution by groups of heights of plants that make up the undergrowth collected. It has been established that the transformation of the undergrowth by an urbanized environment neutralizes the influence of the growing conditions of the considered forest types on it. In the forestpark zone, an increase in the density of the undergrowth is observed in comparison with the natural forest. The specificity of the forest park undergrowth is the floristic contamination with adventive species, the number of which is close to $50 \%$ of the total number of undergrowth species. The coefficient of floristic similarity of the undergrowth, according to the Sorensen coefficient between forest parks and a site of natural forest, was 0.26-0.46. In quantitative terms, the self-seeding of adventive species in the undergrowth is less than that of native plants. The invasive activity of ash-leaved maple in city parks and its dynamics over a 10 -year period are considered, using the example of one of the parks.
\end{abstract}

\begin{abstract}
A brief definition of undergrowth is given by GOST: "Undergrowth includes shrubs, less often trees growing under the forest canopy and unable to form stands in specific growing conditions." [1]. It should be noted that, traditionally, raspberry (Rubus), a sub-shrub, are referred to as undergrowth species. The studies were carried out in pine plantations of forest parks and green zones in the forb and berry groups of forest types in order to assess the parameters of the undergrowth (density, height, species composition) of forest ecosystems transformed by the urbanized environment of Yekaterinburg. For the work, 59 sample plots (SP) were laid with varying degrees of recreational degression in 10 forest areas, including two of them remote from the city, but under the influence of anthropogenic impact (relative control), and one can be considered as control. On the SP, 25 counting sites with a size of $2 * 2 \mathrm{~m}$ were laid at an arbitrary distance in the direction along two diagonals of the SP. The number of undergrowth was estimated by the number of trunks in trees and by the number of trunks in shrubs.

The objective of the study was to assess the parameters of the undergrowth in forest parks, their possible changes under the influence of the urbanized environment, the inclusion of adventive species in the undergrowth and the possibility of replacing them with native species. It has been established that in forest parks the number of undergrowth plants
\end{abstract}


varies from 22 to 61 thousand ind./ha (on average 45 thousand ind./ha), in the green zone from 13 to 30 thousand ind./ha (on average 19 thousand ind./ha) (Fig. 1). The influence of forest growing conditions on differences in the abundance of undergrowth within the considered groups of forest types is not observed. The prevailing height of the undergrowth on most of the PP is $0.2-1 \mathrm{~m}$, but in some forest parks a height of $1.5-2 \mathrm{~m}$ is recorded. The height structure of the undergrowth practically does not change with varying degrees of recreational degression. The undergrowth is dominated by plants with heights from 0.20 to $1.5 \mathrm{~m}$ with different maxima within the layer of shrubs. The number of undergrowth in forest parks is quite clearly associated with the degree of recreational degression and decreases with its increase.

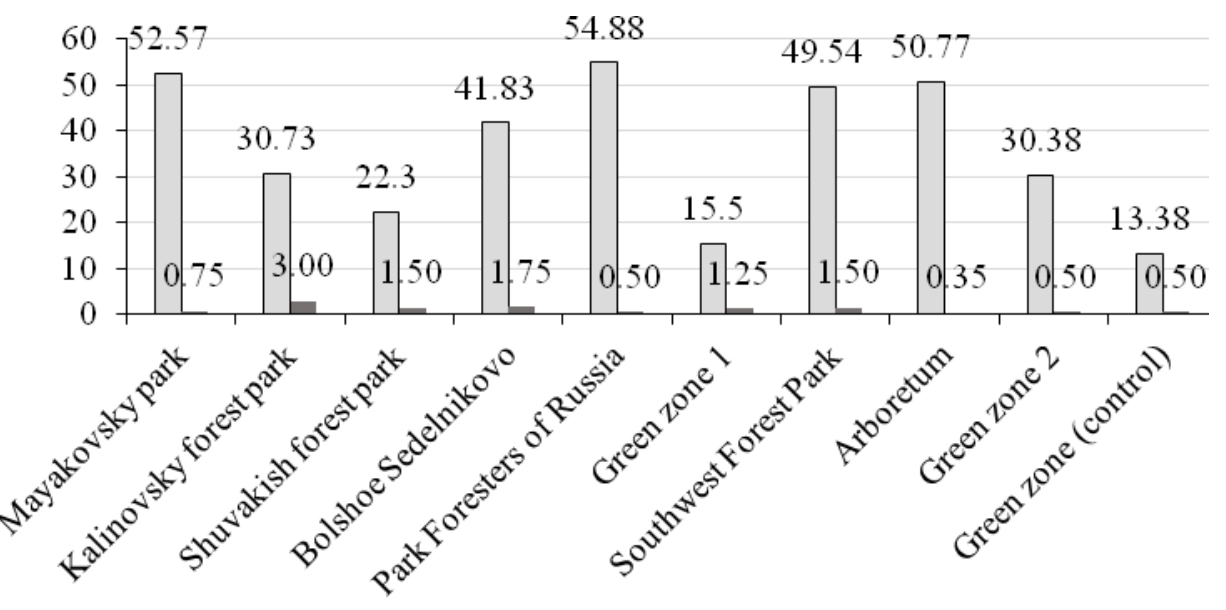

$\square$ Density of undergrowth, thousand ind./ha $\quad \square$ Average height, $m$

Fig.1. The number of undergrowth, thousand ind./ha and its dominant height, $\mathrm{m}$

The occurrence of certain species of undergrowth plants varies widely (1-96\%). The uniform distribution under the canopy is typical on different sample plots for the raspberry Rubus idaeus L. and the bird cherry Padus sp. (Padus avium Mill.), Ash-leaved maple Acer negundo L., apple Malus sp., Mountain ash Sorbus aucuparia L. Raspberries dominate in forest parks in most of the sample plots, often forming continuous thickets. Codominants are Mountain ash, the bird cherry. The frequency of occurrence is: for raspberries - 9-68\%, for mountain ash $31-73 \%$, for bird cherry $0-43 \%$. The active spread of raspberries and mountain ash is directly or indirectly provoked by the proximity of the urbanized environment. Raspberry thickets - are formed both as a result of enrichment of the soil of forest parks with rotting waste and waste products of humans and domestic animals, as well as frequent local runaway fires. The latter are an indirect result of anthropogenic influence on the formation of the undergrowth. In forest parks, the species richness of the undergrowth is higher and numbers from 12 to 24 species, in contrast to the green zones 11-14 species. The differences in the floristic composition are confirmed by the Sorensen coefficient, which was $0.26-0.46$. Thus, statistically significant differences are observed at $\mathrm{p}<0.05$ according to Student's t-test in the species composition of the undergrowth between forest parks and the green zone. A specific feature of the undergrowth of suburban forests is the penetration of naturalized adventive species under the canopy. Otherwise, these species could be designated as self-seeding of introduced species, emphasizing that they were deliberately introduced by humans. When considering the species richness of the undergrowth by the degrees of recreational degression, it was found that, first of all, the species composition of self-seeding of introduced species is influenced by the proximity of 
their source of seeding, and not by the area of disturbed soil cover. The distribution of adventive species occurs mainly in the zoochoric and anemochoric pathways. There are slightly fewer native forest species in forest parks (6-11) than in the control (10-12). The smallest number of adventive species was recorded in the green zone in the relative control (2-4) and in the control (1) (Fig. 2).

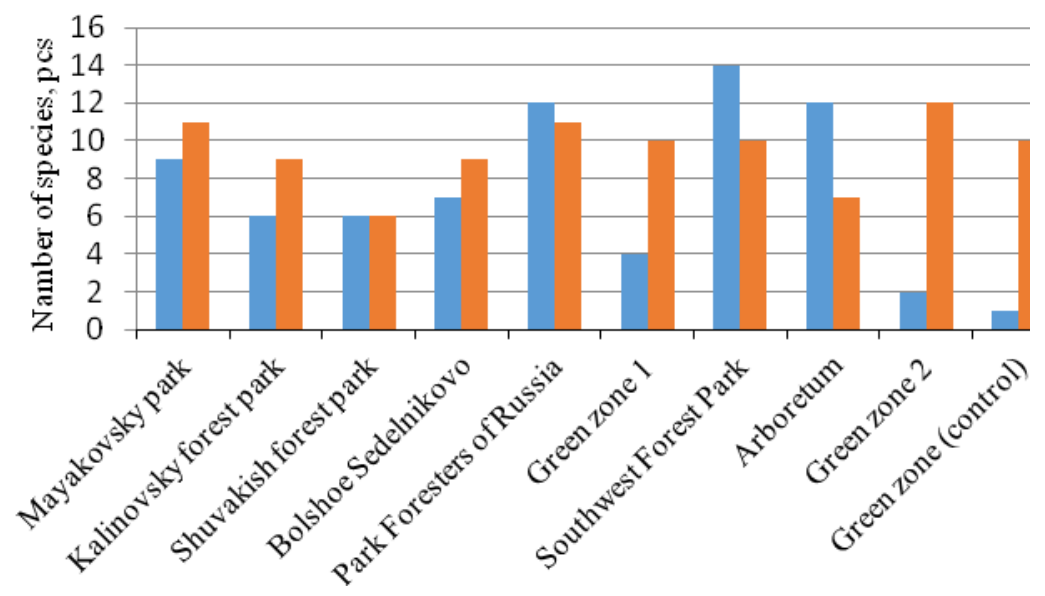

Fig. 2. The ratio of the number of native forest and adventive species in the forest-park and green zones

In quantitative terms, there are fewer adventive species plants in the undergrowth, and often significantly less than native species plants (Fig. 3).

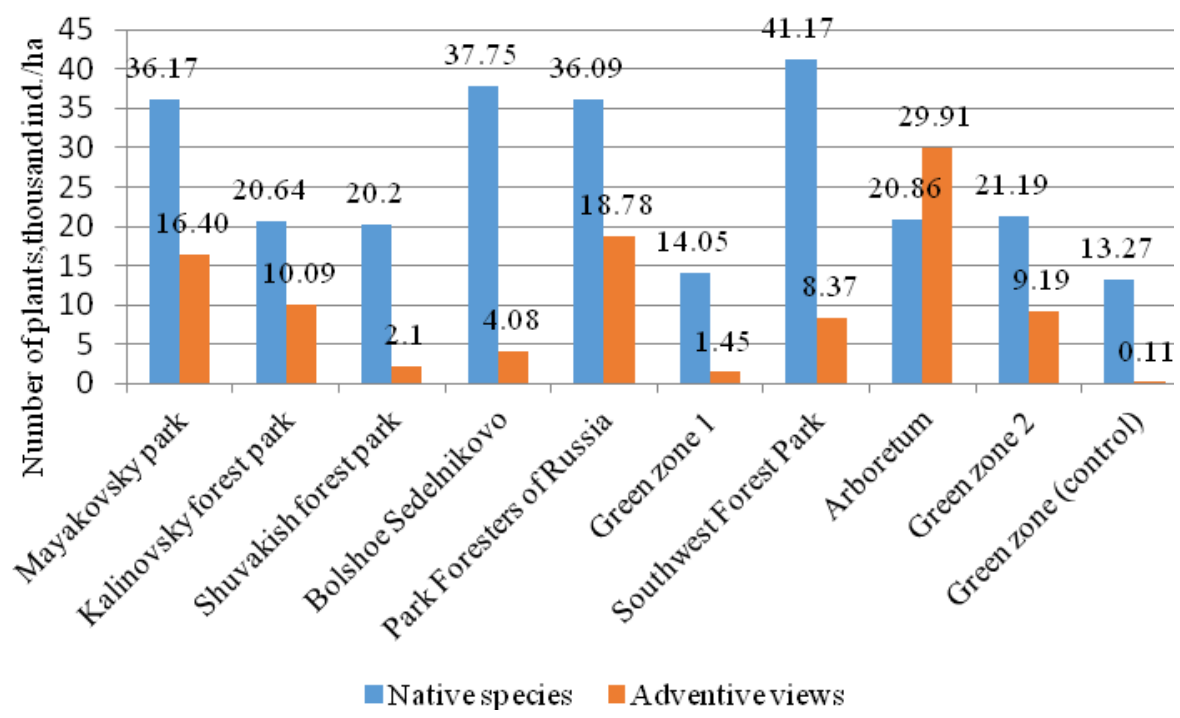

Fig. 3. The ratio of the number of plants of native forest and adventive species in the forest-park and green zones 
However, in connection with the floristic pollution of the undergrowth, the question arises about the degree of invasive danger and the forecast of the development of the adventive component of the flora. Of the adventive species we have encountered, the ashleaved maple (Acer negundo L.) [2-5], which is listed in the Black Book of Flora of Central Russia, Black Book of Siberia [4] is considered the most aggressive. We registered this species in all forest parks. In four of them, the abundance of ash-leaved maple is significant: the maximum was in the Central Park of Culture and Rest (or Mayakovsky Park) about 9 thousand ind./ha, 1.49 thousand ind./ha each in the South-West forest park and arboretum, 0.94 thousand ind./ha in the Lesovodov Rossii Park (Fig. 4). In addition to the abundance indicator, for assessing the invasive potential of ash-leaved maple, the vertical structure of its renewal, distribution (even, by biogroups) along the SP and over the park area are important. In forest parks, ash-leaved maple plants with a height of up to 0.5 $\mathrm{m}$ prevail. Individuals that have reached 3 or more meters are observed only in the Mayakovsky Park and the South-West Forest Park, but it is they who, in our opinion, pose the greatest threat to the aboriginal phytocenosis.

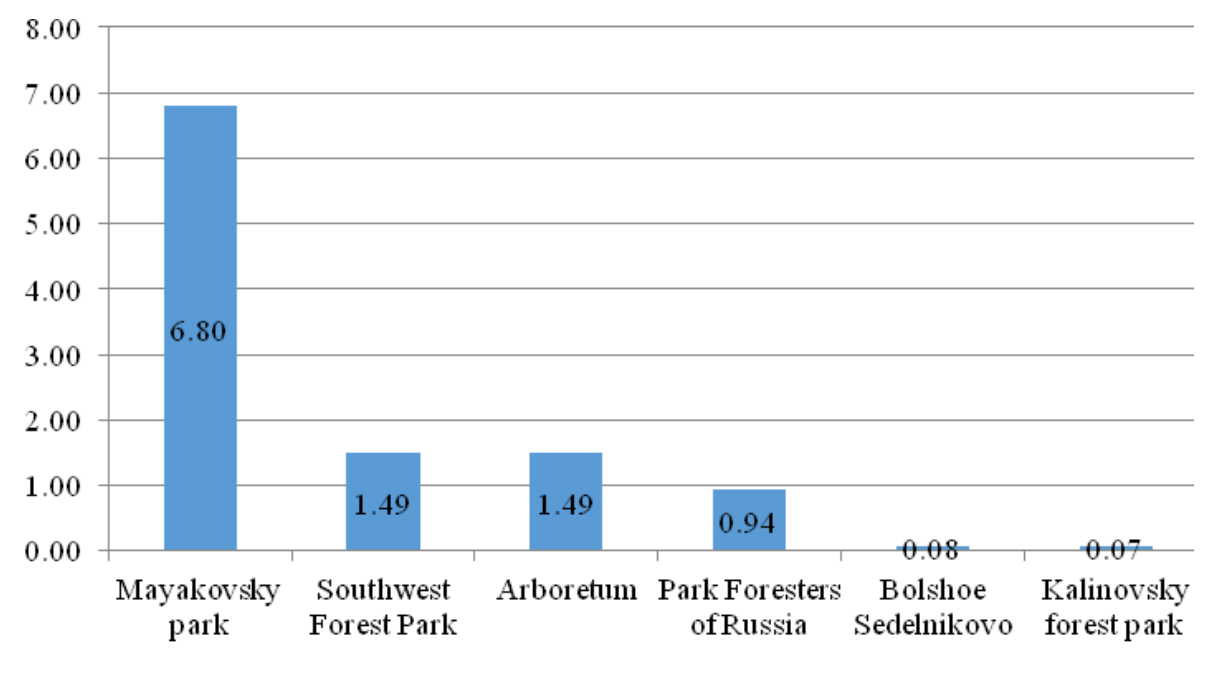

ácer negúndo, thousand ind./ha

Fig. 4. The number of ash-leaved maple, thousand ind./ha

Let us dwell on a more detailed consideration of the invasive activity of ash-leaved maple in the Central Park with an assessment of its expansion over a 10-year period. This park is a forest area of about 64 hectares, indented by a road and path network.

During the improvement of the Park, the introduction of species of shrubs not typical for the forest environment was carried out. An additional introduction of seeds of adventive species under the forest canopy took place at the expense of the seeds of introduced urban landscaping, since the park is surrounded by urban buildings. At the initial count, it was found that the maximum number of ash-leaved maple plants is concentrated in the forest edge - 19.9 thousand ind./ha, including 1.2 thousand ind./ha of large individuals. When moving into the depths of the forest, a decrease in the number of maple plants to $3.3-3.7$ thousand ind./ha was noted, including large $0.2-0.8$ thousand ind./ha. The average occurrence of this species in the park is $34 \%$. In the gradient - edge - center of the park, it changes as follows: $68-60-36 \%$. The average occurrence of this species in the park is $34 \%$. In the gradient - edge - center of the park, it changes as follows: $68-60-36 \%$. The occurrence of large individuals $(1.5-3 \mathrm{~m})$ in the same gradient is $36-36-16 \%$. From the analysis of the combination of the abundance and occurrence of large ash-leaved maple 
plants, it follows that they grow in rather dense biogroups with the expansion of the territory by smaller individuals.

Repeated counts of the parameters of the undergrowth in the park showed that after 10 years the average number of ash-leaved maple plants increased by $27 \%$. The greatest increase in the number is observed in the group of plants in height from 20 to $50 \mathrm{~cm}$ (by 1.7 thousand ind./ha) and in the group from 1.5 to $2.0 \mathrm{~m}$ (by 0.7 thousand ind./ha).

At the edge of the forest, the number of ash-leaved maple plants did not change significantly, but at the far from the edge of the SP, it increased 2 times, mainly due to plants in the height range from 20 to $200 \mathrm{~cm}$. In the gradient from the edge to the center of the park, the occurrence also increased and amounted to: $84-64-72 \%$. Consequently, there is a successful advance of ash-leaved maple to the central part of the forest.

The general parameters of the undergrowth in the Park over 10 years have changed as follows: the density increased from 52.57 to 55.32 thousand ind./ha, the number of plants of adventive species from 16.40 to 25.20 thousand ind./ha, the number of aboriginal species decreased from 36.17 to 30.13 thousand ind./ha.

Thus, under the influence of urbanized environment in forest parks, the density of the undergrowth increases, floristic pollution by adventive species and invasive processes are observed as consequences of introduction, quantitatively, there is an excess in the composition of the undergrowth of native species over adventive ones.

\section{References}

1. GOST 18486-87 Forestry. Terms and definitions, 18 (1988)

2. N. Panasenko, Plants Bulletin of the Udmurt University, Biology 2 (2013)

3. A. Tretyakova, Russian Journal of Biological Invasions, 8(4) (2015)

4. A. Tretyakova, Bulletin of Udmurt University, Biology, Earth sciences 26(1) (2016)

5. D. Veselkin, A. Korzhinevskaya, E. Podgaevskaya, Bulletin of Tomsk State University, Biology, 42 (2018) 